\title{
Collecting COVID-19 at National Museums Scotland
}

\author{
Sarah Laurenson, Calum Robertson, Sophie Goggins
}

National Museums Scotland (NMS) is a multi-disciplinary institution, collecting across five departments: Art \& Design, Natural Sciences, Scottish History \& Archaeology, Science \& Technology, and World Cultures. Working with registrars and conservators, curators from all areas collect the contemporary. We work collaboratively to document both change and continuity, to illuminate the ways in which the present continually reshapes our understandings of Scotland and the world. In a short time, collecting COVID-19 has brought aspects of this collaborative work to the fore - as we are in a position to view the impact of coronavirus from a number of angles - and has forged new acquisitions procedures and practices.

In the week before the COVID-19 preventive lockdown was announced in March 2020, staff from across National Museums Scotland made preparations to close and work from home. At the same time a team of collections staff was finalizing an internal paper titled 'Collecting COVID-19 at National Museums Scotland', outlining our approach to documenting the impact of the coronavirus. As curators dealing with the contemporary in Scottish History \& Archaeology and Science \& Technology in particular, we sought to anticipate the trajectory of government guidelines and new legislation against a backdrop of rapid change and growing uncertainty. One of the final points already reads like a piece of history: 'As the situation develops and these [social distancing] measures are enforced, we will collect around the impact of the police service and the armed forces in day-to-day life'. From beginning to end, the collecting plan is couched in the language of uncertainty - 'if' and 'what might be' and 'we may'. Issues with verb tenses underline the difficulties of planning what to collect and when, at a point where we hoped the social and cultural impact we sought to represent would, in the end, be minimal. Now, ensconced at home and communicating digitally, this piece reflects on collecting activity across our distinct but interlinked areas of curatorial responsibility: social, medical and military history.

From the start, the emphasis of our collecting has been on representing the impact of COVID-19 across Scotland as it unfolds, through tangible, 3-dimensional objects, supported by digital and print material, and pursued with 'the highest levels of sensitivity' [original emphasis]. In practical terms, we are earmarking objects for collection and processing when our buildings reopen and staff are back on site.

Our plan for collecting is divided into six main areas: public health, hospitals and treatment; politics; economy; tourism; education; and everyday life. One of the first objects we secured was a face shield made by a teacher at Lochaber High School in the Highlands using a 3D printer, then finished with plastic panels and delivered to local Belford hospital by Lochaber Mountain Rescue Team. This object crosses several areas outlined in our plan: the impact on the National Health Service (NHS), personal protective equipment (PPE) shortages, the community response and finally, if tangentially, school closures. We have taken steps to ensure that such objects are not diverted from frontline workers, instead securing an example with an informal agreement and a view to following up later. In other areas, we have made contact with individuals through personal and professional networks - for example, an intensive care unit doctor and a respiratory physiotherapist working with COVID-19 patients and agreed to enter into discussions when the crisis is over. At the other end of the spectrum, we have secured several representations of that ubiquitous symbol of happiness and hope: the rainbow. A drawing from Edinburgh together with a pebble painted on a stone from a doorstep in Shetland help us document the impact, and the response, across the country.

Museum \& Society, November 2020. 18(3) 334-336 @ 2020, Sarah Laurenson, Calum Robertson, Sophie Goggins. ISSN 1479-8360 
Representing a wide geographical spread is central to the contemporary collecting programme, but poses challenges during lockdown when we cannot travel. We would ideally visit different parts of Scotland to gather material and listen to a range of perspectives, documenting how the coronavirus is affecting everyone across the country in different ways according to particular social, geographical and economic factors. For example, it is important that we collect one of the many signs posted by members of the public in rural communities asking visitors not to enter, reflecting Scottish Government guidance not to travel to islands or beauty spots. Such material documents the economic impact on rural communities which rely heavily on tourism, and concerns about visitors quarantining themselves in areas where the nearest intensive care unit is hundreds of miles away, and which, in some cases, are reliant on new measures for evacuation by the Royal Air Force. We are also collecting cultural and community responses in the islands, including Skye, where businesses, artists and makers have staged a successful fundraising campaign for volunteer teams working to support residents during the crisis.

This is not our first experience of collecting around a public health crisis; collecting objects relating to Scotland's experience of the 2014 Ebola epidemic proved to be sensitive and difficult. Ephemera and commonplace items - such as posters at entry points into the country - proved impossible to collect. People and organizations would often point us to websites where we could print our own, misunderstanding the importance of authenticity in museum practices. These issues were at the forefront of our minds while trying to collect similar objects - such as signs to facilitate social distancing in supermarkets - around COVID-19.

We have used existing relationships to try to acquire other objects, such as specialized medical and research equipment. While these objects remain in essential use, 'Post-it Note' collecting allows us to identify potential acquisitions and return to them in due course. This method, while useful, does not always bear fruit. It relies on institutional memory from both the museum and the donor. While such medical objects as ventilators are central to the story of COVID-19, they can lack specific human stories and emotional connection for our visitors. To address this, we have collected, for example, a pair of knitted hearts from NHS Greater Glasgow and Clyde which physically and metaphorically connect patients with the loved ones from whom they are separated. These stories support and personalize the experience of COVID-19 treatment.

The tragic circumstances of the COVID-19 pandemic have also acted as catalysts for thinking critically about the relationship between the armed forces and contemporary Scottish society, and the ways in which we continue to collect the material evidence of Scottish military service. Personnel from all three armed services have played a vital role in the pandemic response across the United Kingdom. In Scotland, we have seen regular and reserve soldiers work together to manage mobile testing centres and deliver PPE, whilst RAF aircrews have airlifted COVID patients from island communities to specialist medical facilities on the mainland. Thinking particularly about military reservists, we are preparing to collect objects that articulate the adaptations service personnel have made. These adaptations encompass all aspects of life and work (managing civilian occupations and the challenges of family life), including specialist auxiliary medical training and kit.

The creation of Scotland's temporary emergency critical care hospital, NHS Louisa Jordan, is also of interest within the context of military collecting. The Scottish Government chose not to follow the UK Government's decision to use the 'Nightingale' name for such facilities, preferring to honour the name and legacy of Louisa Jordan, a nurse with the Scottish Women's Hospital (SWH) who died in 1915 whilst serving in Serbia. In producing the feasibility study for the hospital at Glasgow's SEC Centre, the army played an important but limited role in the installation. Although the hospital has not, to date, been required, its management would have relied heavily on retired military personnel and others with skills and experience of building medical installations in crisis situations. Here we see a more nuanced picture of the military experience in contemporary society; cooperative working across military and civilian agencies built on the training, experiences and networks of exservice personnel. Discussions are ongoing with Scottish military veterans involved in the running of the hospital to ensure that appropriate material reflecting their experiences and 
contributions can be retained by the museum. NMS has an existing collection of First World War SWH material, and the contemporary reception of Louisa Jordan and the SWH during this pandemic is something we will seek to collect.

The political dynamics of COVID-19 in Scotland are impossible to ignore. Key aspects of the nation's pandemic response centre on politically devolved areas such as health, policing and education, resulting in both a tangible divergence from UK Government policy and public health communication, and tension in specific areas that remain reserved to Westminster. (For example, Scotland's reopening plans operated on a different timetable to England.) It is impossible to predict the long-term effects of these policies, either politically or with regards to the health of the nation; however, it is clear that this pandemic is the single greatest challenge a Scottish devolved administration has faced since the re-establishment of the Scottish Parliament in 1999. It is crucial, therefore, that whilst we collect material that documents a range of social, medical and military responses to COVID-19, we ensure that this material is interpreted within the context of Scotland's ongoing political dialogue and journey. No doubt this attention to the subtleties of differences in policy, response and experience of the pandemic within and between nation-states will be applicable in other contexts. In a globalized environment, collecting with an emphasis on that which is distinctive about Scotland inevitably reflects the manner in which wider social, cultural and political changes are felt in this country. This has rarely been more immediate than with the impact of COVID-19.

Received: 9 June 2020

Finally accepted: 12 June 2020

\section{Authors}

Sarah Laurenson, Calum Robertson, Sophie Goggins

\section{Biographical note}

All three authors are curators at National Museums Scotland. Sarah Laurenson (Curator, Modern \& Contemporary History) and Calum Robertson (Curator, Modern \& Military History) are in the Department of Scottish History \& Archaeology. Sophie Goggins (Curator, Biomedical Science) is in the Department of Science \& Technology.

\section{Correspondence addresses}

Calum Robertson

Department of Scottish History \& Archaeology

National Museums Scotland

Chambers Street

Edinburgh

EH1 1JF

ca.robertson@nms.ac.uk

+44(0)1312474373 